\title{
Insegurança Jurídica do Devedor: pela Ampliação do Debate sobre Seleção Adversa e Custo do Crédito no Brasil*
}

\section{Jurisdictional Insecurity from the Debtor's Perspective: a Broader Debate on the Effects of Adverse Selection and Costs of Credit in Brazil}

\author{
Luciana Luk-Tai Yeung** \\ Ana Lúcia Pinto da Silva*** \\ Carlos Eduardo Carvalho****
}

Resumo: $\mathrm{O}$ artigo defende que a insegurança jurídica no crédito afeta também o devedor. O debate econômico brasileiro praticamente ignora problemas dos tomadores de crédito diante de procedimentos desleais e oportunistas dos credores. Para a teoria econômica dos contratos, o credor é a parte favorecida pela assimetria de informações sobre o mercado, e o agente da lei deve atuar de forma a corrigir esse desequilíbrio. A análise de 1.687 decisões do Superior Tribunal de Justiça, de 1998 a 2008, não revela viés anticredor nesse nível do Judiciário. O trabalho propõe a inclusão da insegurança jurídica do devedor no modelo de racionamento de crédito.

Palavras-chave: Insegurança jurídica. Custo do crédito. Seleção adversa.

Abstract: This paper argues that jurisdictional insecurity also harms debtors. Economic debate in Brazil practically ignores the problem of unfaithful and opportunistic creditor behaviors. Economic theory of contract assures that creditors have more information about the market, and they are, therefore, in an advantageous position and law should act in order to correct this unbalance. The analysis of 1,687 judicial decisions by the Superior Tribunal de Justiça (Supreme Court of Justice), during years 1998 to 2008, does not reveal anti-creditor bias at this level

\footnotetext{
* Versão revista e ampliada do trabalho "A insegurança jurídica é também do devedor: seleção adversa e custo do crédito no Brasil", publicado na coletânea Trinta anos de Brasil: diálogos entre Direito e Economia (2011), organizada por Maria Lucia de Pádua Lima.

** Doutora em Economia pela Fundação Getúlio Vargas (FGV/SP). Professora de Economia do Insper (São Paulo). E-mail: lucianay@insper.edu.br

*** Doutora em Economia pela FGV/SP. Professora de Economia da Universidade Presbiteriana Mackenzie.E-mail: lucinhaps@uol.com.br

**** Doutor em Economia pela Universidade Estadual de Campinas (Unicamp). Professor do Departamento de Economia da Pontifícia Universidade Católica de São Paulo (PUC/SP). E-mail: cecarv@uol.com.br
} 
of the Judiciary. The paper proposes the inclusion of debtor's jurisdictional uncertainty in credit restriction model.

Keywords: Jurisdictional uncertainty. Cost of credit. Adverse selection.

JEL Classification: E50; G14; K40.

\section{1 lntrodução}

As implicações da insegurança jurídica quanto ao cumprimento dos contratos têm sido discutidas na literatura econômica como um dos determinantes para o baixo desenvolvimento do crédito privado de médio e longo prazos e para os altos spreads praticados pelos bancos no Brasil. Diante da expectativa de dificuldades e morosidade para execução de garantias e da baixa previsibilidade das decisões judiciais em caso de litígio com o devedor, os bancos restringiriam a oferta de crédito e embutiriam uma margem adicional no custo das operações, com prejuízos para o tomador de menor risco e para a atividade econômica em geral.

Essa literatura, contudo, trata a insegurança jurídica de forma unilateral, como se fosse um problema apenas do credor, e ignora a existência de insegurança jurídica também para o devedor. Para o tomador de crédito, a incerteza é gerada porque o banco pode adotar atitudes não previstas ou previstas de forma insuficiente no contrato inicial (cobrança de taxas adicionais, exigência de reciprocidades), fazer exigências descabidas no caso de dificuldades de pagamento pelo devedor e negar a renovação do crédito ou exigir condições muito desfavoráveis para a renovação. O tomador de crédito está diante do risco de práticas desleais ou oportunistas por parte do banco e está sujeito a condições muito adversas em caso de dificuldades de pagamento.

Diante do custo de elaboração e de monitoramento dos contratos, o tomador de crédito é a parte mais fraca, por não conhecer ou por não entender claramente as cláusulas do contrato. Para o credor, não há incentivo para informar adequadamente o devedor sobre as condições dos contratos, o que aumenta de forma considerável a incerteza em que este incorre. Trata-se de um problema de assimetria de informação, desfavorável ao tomador de crédito. Nesses casos, o credor assume a posição do que Cooter e Ulen (2010) denominaram de "tomador de risco mais eficiente" entre as partes que participam da relação contratual. No caso de conflito com o banco, o tomador de crédito também enfrenta a morosidade do processo e a baixa previsibilidade das decisões judiciais.

O problema é agravado pela forte disparidade de poder econômico entre os credores e os devedores em uma disputa judicial. Empreendedores de pequeno porte e pessoas físicas estão em evidente desvantagem no caso de disputa judicial com prazo e resultado incertos. O oponente contará com departamentos jurídicos 
próprios e disporá de recursos para contratar escritórios especializados, enquanto o querelante terá que se afastar da gerência do negócio para acompanhar o caso, com advogados contratados com baixa remuneração.

Frente a tais riscos, a atitude mais racional da empresa ou do empreendedor individual pode ser evitar o uso de recursos dos bancos, para minimizar riscos. Com isso, muitos projetos com boas perspectivas de sucesso não são encaminhados, pela relutância em tomar crédito, e os bancos são induzidos a emprestar para projetos de maior risco. Haveria, assim, uma tendência de seleção adversa dos clientes dos bancos: a demanda de crédito tenderia a se concentrar em projetos de risco alto, com rentabilidade esperada suficiente para compensar a possibilidade de conflito com o credor, ou em projetos já em desequilíbrio financeiro acentuado, em que os custos de conflitos seriam menores que os custos de insolvência. Seria um círculo vicioso, em que os bancos emprestam mais para clientes de maior risco, o que induz spreads mais altos e riscos de inadimplência ampliados, um quadro de repressão financeira em que a demanda potencial de financiamento não é atendida, por receios dos tomadores, e os ofertantes são induzidos a financiar negócios de maior risco.

A ausência de referências a problemas dos devedores na literatura sobre insegurança jurídica é muito grave, diante do elevado volume de queixas e reclamações de tomadores de crédito e de cliente de bancos. A literatura econômica ignora pesquisas empíricas que contestam a tese de que o Judiciário brasileiro tende a decidir sempre em prol do devedor, o que aumentaria a insegurança dos bancos, e também ignora a insegurança jurídica dos tomadores de crédito.

Na literatura jurídica nacional, Falcão, Schuartz e Arguelhes (2006) mostram a existência não de um "viés pró-devedor", mas de um "viés legislativo". Para os autores, o que existe é um viés criado em um momento anterior ao da decisão judicial, durante a elaboração das leis pelo Legislativo e das normas legais pelo Executivo, e os magistrados têm a função e o dever de respeitá-las. Nesse caso, a decisão judicial que favorece uma ou outra parte, "devida" ou "indevidamente", não reflete um viés do juiz, mas da própria legislação em vigor. Os autores enfatizam a relevância de identificar a origem do suposto viés:

[...] [O] fato de o juiz tomar uma decisão contrária ao credor não significa evidentemente que a sua decisão reflita um viés anti-credor cuja origem possa ser identificada na "vontade livre" do juiz. A fonte primária desse viés pode estar tanto nos atos do Poder Legislativo e do Poder Executivo, enquanto responsáveis pela elaboração das normas que o juiz precisa aplicar, quanto nos atos dos agentes econômicos privados - especificamente, do conjunto de credores e devedores diretamente responsáveis pelo conteúdo das cláusulas contratuais submetidas à apreciação judicial (FALCÃO; SCHUARTZ; ARGUELHES, 2006, p. 32). 
O presente artigo propõe que a discussão da insegurança jurídica e de suas implicações sobre o crédito inclua os problemas do devedor. A segunda seção fundamenta a maior vulnerabilidade do devedor, com base na teoria econômica dos contratos, e a terceira caracteriza o debate sobre insegurança jurídica no Brasil. A quarta seção apresenta a análise de 1.687 decisões do Superior Tribunal de Justiça (STJ), pela qual não é possível provar a existência de viés anti-credor nesse nível do Judiciário. A quinta seção propõe a inclusão da insegurança jurídica do devedor no modelo teórico de racionamento de crédito. A sexta e última seção sumariza os principais pontos analisados.

\section{A Teoria Econômica dos Contratos e a Insegurança Jurídica no Crédito}

Para a teoria econômica dos contratos, em toda relação em que um agente econômico faz uma promessa a outro, a ser cumprida em determinado tempo, existe o risco de descumprimento por aquele que promete. O contrato oficializa a promessa e indica previamente qual será a punição caso a promessa não seja cumprida. É a forma institucional de minimizar os riscos de quem acreditou na promessa e fez negócio com base nela. Para Sztajn e Zylbersztajn (2005, p. 104),

[...] um contrato significa uma maneira de coordenar as transações, provendo incentivos para os agentes atuarem de maneira coordenada [...] o que permite planejamento de longo prazo e, em especial, [...] que agentes independentes tenham incentivos para se engajarem em esforços conjuntos de produção.

Os contratos podem ser ainda mais complexos quando existem múltiplas promessas em uma única relação e cada agente tem um rol de obrigações e direitos daí derivados. Por essa complexidade, o contrato não é um instrumento de custo insignificante, um mero detalhe nas transações.

Coase (1937) trouxe os custos dos contratos para o centro da discussão econômica ao propor o que foi depois denominado de "custos de transação" pelos economistas institucionalistas.

Negociar e redigir o contrato tem custos para as partes envolvidas. Quanto mais detalhado for o contrato negociado, maiores serão os custos incorridos. Nessa ótica, o grau de detalhamento dependerá dos riscos que o contrato pode minimizar vis-à-vis o custo de negociá-lo, o custo de transação de formular o contrato.

Se negociar um contrato com inúmeras cláusulas for relativamente barato e permitir grande redução de custos derivados de riscos potenciais, provavelmente o contrato será mais detalhado, mais completo. Se negociar um contrato longo e complexo, com previsão de quase todas as eventualidades, for custoso em comparação com o custo dos riscos potenciais, esse contrato será provavelmente menos completo, com mais lacunas. Caso surjam problemas por conta das lacunas, os 
conflitos deverão ser dirimidos depois pelas partes ou por um terceiro agente, o juiz.

Assim, três elementos determinam o grau de completude do contrato: os custos de transação envolvidos na negociação, os custos potenciais derivados do risco de descumprimento por uma das partes e a probabilidade de esses riscos se tornarem efetivos. A completude do contrato será menor se os custos de transação forem mais altos e será maior se os riscos da quebra contratual forem muito grandes.

Outro fator importante que explica a existência de contratos incompletos é a racionalidade limitada dos agentes econômicos, decorrente dos "[...] limites impostos à habilidade dos seres humanos de se adaptarem otimamente, ou mesmo satisfatoriamente, a ambientes complexos [...]" (SIMON, 1991, p. 132, tradução nossa). No caso dos contratos, os agentes têm limites cognitivos que os impedem de criar relações ou desenhar contratos que consigam "otimamente, ou mesmo satisfatoriamente" minimizar todos os riscos de um ambiente ou de uma transação complexa.

Devido aos custos de transação inerentes à formulação e à execução dos contratos, e com a racionalidade limitada inerente aos agentes econômicos, os economistas institucionalistas não têm dúvida: o contrato perfeitamente completo não existe, pois “[...] contratos são intrinsecamente incompletos" (AZEVEDO, 2005, p.128).

Outra contribuição muito relevante sobre os problemas derivados das relações contratuais vem da análise econômica do Direito (Law and Economics): o conceito de tomador de riscos mais eficiente (efficient risk bearer) como solução prática diante de lacunas de contratos incompletos. Esse agente é o que teria, ex ante, custos menores para evitar uma quebra contratual. Se o contrato é incompleto, é porque eram muitos altos os custos de negociar cláusulas mais detalhadas. Com isso, para identificar o "tomador de riscos mais eficiente" de uma relação contratual, é preciso averiguar qual dos agentes teria sido responsabilizado ex ante pelos custos da quebra, caso a negociação do contrato tivesse sido ampliada.

Para Coase (1960), se os custos de transação são baixos, o resultado da negociação será sempre um resultado que minimiza os custos, o resultado mais eficiente. Cooter e Ulen (2004) indicam uma forma para identificar o "minimizador de riscos mais eficiente" em qualquer situação contratual, por meio de uma barganha hipotética. Quando um conflito ocorre numa relação em que a matéria do conflito não foi tratada previamente pelos agentes e existe uma lacuna, o juiz, ou a pessoa que deve dirimir o conflito, pode supor o que os agentes teriam decidido se a matéria tivesse sido discutida na criação do contrato. Em suma: o juiz deve hipotetizar quem teria sido responsabilizado ex ante pelo conflito. Como Cooter e Ulen (2004, 
p. 215, tradução nossa) afirmam, "[...] o contrato ideal aloca o risco de perdas imprevistas para o minimizador de risco mais eficiente."

A teoria econômica dos contratos mostra que, em uma relação contratual entre um consumidor e uma firma, na maioria absoluta das vezes a firma é o tomador de risco mais eficiente: ela é especialista no negócio - sua atividade econômica baseia-se na atuação nesse setor - e tem as informações relevantes sobre o mercado, e, se não as tem, é certamente a parte que tem menos custos para consegui-las. Ou seja, na relação comercial contratual existe assimetria de informação em favor da firma.

As instituições financeiras atuam no mercado de crédito, pois é o seu negócio, e têm muito mais informações: são mais capazes de prever riscos, ganhos e perdas potenciais. Quando não possuem essas informações, é muito difícil que clientes possam tê-las com custos menores.

Assim, o tomador de empréstimo é a parte desfavorecida na relação contratual, devido à assimetria de informação sobre o mercado de crédito e sobre o próprio contrato. Sem a proteção de um terceiro agente, como o agente da lei, torna-se ainda mais acentuada a maior vulnerabilidade do devedor na relação contratual.

A lei reconhece esse indivíduo como mais vulnerável. O direito do consumidor brasileiro identifica o agente hipossuficiente como aquele economicamente mais fraco. Na relação de consumo, o consumidor é sempre o agente hipossuficiente e o demandante de crédito junto ao banco. Por não atuar profissionalmente na área e não dispor de meios baratos para obter as informações necessárias, deve ser considerado o agente hipossuficiente.

O emprestador (banco, outras instituições de crédito, etc.), por ser um atuante profissional no negócio, é o minimizador de custos mais eficiente. Isso é ainda mais verdade porque o contrato de empréstimo e todas as condições derivadas são, na maior parte das vezes, criadas e oferecidas unilateralmente pelo banco ao tomador. Além da dificuldade maior para entender a transação em si, o cliente deve ainda entender o contrato desenhado integralmente pelo banco. A assimetria de informação e os custos de transação pesam muito desfavoravelmente para o seu lado. Em uma situação assim, certamente o banco teria muito menos custos para prever os riscos da transação do que seu cliente.

\section{Enfoque Unilateral no Debate Brasileiro}

O debate econômico brasileiro sobre as relações entre insegurança jurídica e crédito está dominado por uma visão unilateral em que apenas os problemas do credor são objeto de análise. Esta seção apresenta de início o trabalho de Arida, Bacha e Lara-Resende (2005), representativo da tendência dominante no debate 
econômico a respeito, e, em seguida, destaca alguns trabalhos que contestam essa tese e tratam do tema pela ótica do devedor.

\subsection{Defesa Unilateral dos Credores: A Posição Dominante no Debate Econômico}

O trabalho de Arida, Bacha e Lara-Resende (2005) teve grande influência, com a defesa de que a incerteza jurídica é a principal razão para o não desenvolvimento do mercado de crédito de longo prazo, por impedir a transferência intertemporal de recursos:

It is an uncertainty of a diffuse character that permeates the decisions of the executive, legislative, and judiciary and manifests itself predominantly as an anti-saver and anti-creditor bias. The bias is not against the act of saving but against the financial deployment of savings, the attempt to an intertemporal transfer of resources through financial instruments that are, in the last analysis, credit instruments (ARIDA; BACHA; LARA-RESENDE, 2005, p. 270).

O viés negativo não seria contra a atividade empresarial, mas sim contra os credores. Para os autores, o problema é amplo e decorre de valores generalizados na sociedade em favor do devedor, apresentado de forma positiva, em detrimento do credor, associado a atividades e condutas pouco nobres. (ARIDA; BACHA; LARA-RESENDE, 2005, p. 270-273).

A manifestação básica do problema seria a dificuldade de garantir que o Judiciário defenda o acesso às garantias:

The quality of enforcement of guarantees is poor because both the law and the jurisprudence are biased towards the debtor. Even if the creditor has sufficient knowledge of the debtor and feels comfortable to lend to him for a long period, jurisdictional uncertainty will make his credit illiquid [...] Bilateral relationships might work but jurisdictional uncertainty precludes the possibility of multilateral impersonal transactions that involve credit over long time periods. The consequence is the almost complete collapse of a long-term financial market (ARIDA; BACHA; LARA-RESENDE, 2005, p. 274-275).

A existência desse viés é supostamente comprovada por Lamounier e Souza (2002, p. 277): "The depth of this bias in Brazil may be inferred from the answers to a recent elite opinion survey conducted by two Brazilian political scientists". Contudo, esse trabalho está baseado em um questionário respondido por juízes, e não em uma análise das decisões tomadas, realizada com método estatisticamente significativo. Resultados de surveys como esse, apesar de relevantes para caracterizar o problema, não representam comprovação empírica nem devem ser usados como representativos da população como um todo. 
Por fim, os autores reclamam que as autoridades e o Judiciário devem rever as formas como o problema tem sido tratado no país:

Policy decisions detrimental to holders of financial instruments are directly responsible for Brazil's jurisdictional uncertainty [...] Independently of the innumerous measures directly hurting the holders of financial instrument most economic policy decisions that aggravated jurisdictional uncertainty were probably a consequence of mistaken attempts to correct its effects (ARIDA; BACHA; LARA-RESENDE, 2005, p. 277).

\subsection{Alguns trabalhos que contestam a tese de que os credores sempre perdem}

Silva (2006) e Golek (2005) elencam modalidades de abusos dos bancos, como venda de produtos induzida, informações incorretas, má-fé em propostas de negociação "irrecusáveis" de débitos inflados por cálculos incorretos. Diversos trabalhos empíricos, ademais, sustentam que os bancos têm grande espaço para tomar atitudes desleais contra os clientes e contam com a proteção da Justiça em boa parte dos casos.

Dois trabalhos apresentaram refutações empíricas dos argumentos de Arida, Bacha e Lara-Resende (2005). Gonçalves, Holland e Spacov (2007) criaram um modelo e proxies para medir o grau de incerteza jurídica e testar a hipótese de Arida, Bacha e Lara-Resende (2005) de que essa incerteza jurídica é a causa das altas taxas de juros no Brasil. Apesar de positivamente correlacionadas com os juros de curto prazo, nenhuma das cinco variáveis de incerteza jurídica medida por Gonçalves Holland e Spacov (2007) resultou em evidências fortes a favor da tese de Arida, Bacha e Lara-Resende. A conclusão é que a incerteza jurídica não explica de forma satisfatória os níveis e a dispersão das taxas de juros de curto prazo. Para estes autores, ao invés das medidas de incerteza jurídica, os fatores monetários e fiscais parecem ser os principais determinantes dos juros de curto prazo no país.

Ferrão e Ribeiro (2007) mostram que o chamado ativismo judicial é difícil de acontecer, inclusive por problemas na ascensão profissional dos juízes na carreira. Além da análise teórica, a pesquisa incluiu a análise e regressão econométrica de 181 decisões judiciais, em 2004 e 2005, avaliando se o contrato foi cumprido e se a decisão foi favorável à parte mais fraca. Os resultados mostraram que a) a parte mais forte tem $39 \%$ mais chance de ter o contrato mantido na forma que lhe favorece; b) a hipótese de favorecimento judicial da parte mais fraca não foi comprovada; c) a parte mais forte, que tem cláusulas contratuais a seu favor, tem $45 \%$ a mais de chance de ter o contrato mantido a seu favor, se comparado a uma parte mais fraca, que também tenha uma cláusula contratual a seu favor. Os autores 
concluem afirmando que o favorecimento acontece de forma consistente para a parte mais forte da relação contratual.

\section{Uma Avaliação Empírica de Decisões do STJ}

Apresentam-se a seguir os resultados da análise de decisões tomadas pelo STJ nos processos que envolveram recursos especiais referentes a dívidas privadas, de outubro de 1998 a outubro de 2008. Estão inclú́dos todos os 1.687 processos que envolveram dívidas desse tipo e que foram efetivamente decididos pelo STJ no período. Todos esses processos foram consultados e foram classificados pelos critérios propostos, apresentados adiante.

A análise dos dados não permite comprovar a existência de viés pró-devedor nas decisões do STJ, e, em muitas situações, o STJ tende a emitir decisões favorecendo o credor. Para evitar o envolvimento em questões puramente processuais, uma das características mais criticadas do Direito brasileiro, somente os recursos especiais foram incluídos na amostra, excluindo-se quaisquer tipos de embargos e agravos. Os recursos especiais são recursos de apelação contra decisões dos Tribunais dos Estados e do Distrito Federal e dos Tribunais Regionais Federais, ou seja, dos tribunais de segunda instância. Segundo Gaio Júnior (2008), o pressuposto do recurso especial é a existência de divergência entre a decisão inferior e uma lei federal.

Dado o objetivo principal deste trabalho, a análise foi limitada a processos que envolviam conflitos sobre dívidas, contratuais ou não. Foram excluídos todos os casos em que o Estado era uma das partes do processo. Dessa forma, não entrou na amostra nenhum processo que tivesse entes públicos como parte recorrente ou recorrida: União, Estados, Prefeituras, Fazenda Nacional, Fazendas Estaduais e autarquias.

Finalmente, foram incluídos todos os processos julgados pelo STJ de 06 de outubro de 1998 a 05 de outubro de 2008. Optamos por iniciar a análise exatamente dez anos depois de criado o STJ, com a promulgação da Constituição, em 05 de outubro de 1988, período suficientemente longo para que se consolidassem as novas leis criadas e o próprio funcionamento do STJ, que começou a julgar efetivamente no início de 1989.

De acordo com Veçoso et al. (2014), infelizmente as bases eletrônicas disponibilizadas pelos tribunais superiores, entre eles o STJ, não contemplam a totalidade dos julgamentos feitos. No entanto, dos processos disponibilizados, esgotamos aqueles relacionados ao tema em questão.

Assim, nesse prazo de dez anos, com os filtros mencionados, foi obtido o conjunto de 1.687 recursos especiais julgados pelo STJ, correspondente ao total de recursos especiais do período referentes a dívidas privadas.

A Tabela 1 divide as decisões do STJ em relação às partes envolvidas, pela condição de credor ou devedor no processo, com predomínio de decisões pró-credor. 
Tabela 1 - Decisões do STJ sobre recursos especiais, de acordo com a parte vencedora (em \%): 1988-2008

\begin{tabular}{l|c}
\hline Decisões pró-devedor & $44,2 \%$ \\
Decisões pró-credor & $53,6 \%$ \\
\hline
\end{tabular}

Fonte: Elaboração própria a partir de dados do STJ.

Nota: Algumas decisões podem não favorecer nem um nem outro, pois algumas partes litigantes não eram nem uma nem outra coisa. Em alguns poucos casos, no meio do processo, ou até mesmo desde o começo, uma parte terceira - por exemplo, o cônjuge ou o sócio de um indivíduo devedor - depositou processos reclamando de alguma decisão judicial ou de alguma situação que lhes desfavoreceu. Nesses casos, quando a decisão do STJ favorece esta parte - que não é a parte devedora, nem a credora - a decisão foi considerada "pró-outros".

A Tabela 2 classifica os dados de acordo com a condição de hipossuficiência de uma das partes envolvidas. Criou-se uma escala de hipossuficiência na qual: pessoas físicas são a parte mais hipossuficiente; empresas estão no nível intermediário de hipossuficiência; instituições financeiras e grandes empresas estatais ou multinacionais são a parte menos hipossuficiente.

Tabela 2 - Decisões do STJ sobre recursos especiais, de acordo com a parte considerada hipossuficiente (em \%): 1988-2008

\begin{tabular}{c|c}
\hline Decisões pró hipossuficiente & $39,2 \%$ \\
Decisões contra hipossuficiente & $47,7 \%$ \\
\hline
\end{tabular}

Fonte: Elaboração própria a partir de dados do STJ.

Nota: Algumas decisões podem não favorecer nem um caso nem outro, pois as duas partes litigantes foram avaliadas como tendo o mesmo grau de hipossuficiência.

Em suma, das 1.687 decisões judiciais analisadas, 746 decisões foram a favor do devedor, $44,2 \%$ do total, e 905 foram a favor do credor, $53,6 \%$ do total. Além disso, $39,2 \%$ das decisões favoreceram a parte hipossuficiente, contra $47,7 \%$ a favor da parte mais forte da relação.

Arida, Bacha e Lara-Resende (2005) afirmam em seu artigo, sem apresentar qualquer tipo de evidência empírica, que existe um viés pró-devedor pela jurisprudência brasileira, ou seja, que os juízes favorecem mais os devedores em suas decisões nos tribunais. A análise de quase 2.000 decisões do STJ, em dez anos, não mostra a existência desse viés.

Assim, a questão da presença de viés pró-devedor ou pró-credor é muito mais complexa e certamente é não uniforme, ao contrário do que defendem Arida, Bacha e Lara-Resende (2005), e requer mais estudos empíricos.

\section{A Insegurança Jurídica do Devedor no Modelo de Racionamento de Crédito}

O mercado de crédito é caracterizado pela incerteza dos agentes no fechamento dos contratos, e a assimetria de informações cria distorções de preços e 
racionamento de crédito. No modelo tradicional, a assimetria ocorre porque as partes envolvidas têm informações diferentes (assimétricas) sobre o produto ou serviço negociado. No mercado de crédito, a informação assimétrica está associada principalmente a dois problemas: a) risco moral, que ocorre quando, após o contrato, a parte menos informada é a primeira a tomar a decisão, sem conhecer a ação a ser tomada pela parte mais informada; e b) seleção adversa, que ocorre quando, antes do contrato, uma das partes envolvidas possui informação imperfeita sobre a outra parte, que é completamente informada, porém a parte menos informada toma a decisão primeiro. ${ }^{1}$

O risco moral no crédito existe porque a condução do empreendimento financiado é observada apenas parcialmente pelo credor, devido a custos de monitoramento muito altos. Com isso, o devedor tem incentivos para aplicar os recursos em atividades com retorno e riscos de inadimplência mais elevados.

A proposta aqui apresentada é discutir a ocorrência de racionamento de crédito causado por seleção adversa decorrente de insegurança jurídica do devedor. Trata-se de incluir, no debate sobre a persistência dos elevados spreads bancários no Brasil, a insegurança jurídica existente do lado do devedor, questão praticamente ignorada no debate econômico brasileiro.

$\mathrm{Na}$ abordagem microeconômica sobre os efeitos da assimetria de informação no mercado de crédito, a seleção adversa ocorre porque os tomadores conhecem melhor sua capacidade de saldar a dívida, mas essa capacidade de pagamento difere entre os tomadores. Se as instituições cobram a mesma taxa de juros de todos os tomadores, atraem projetos de maior risco e maior probabilidade de inadimplência, o que induz à elevação dos juros, com nova rodada de atração de tomadores de maior risco e de afastamento de tomadores de menor risco. Em suma: cresce a proporção de tomadores com projetos mais arriscados dentro do grupo de indivíduos que tomam crédito.

A seleção adversa de tomadores de empréstimos pode ser entendida como a seleção, pelos bancos, de um grupo específico de clientes que difere, em determinados atributos de risco, da média observada na população total. Sendo assim, é a seleção, por parte dos bancos, de uma carteira de clientes com determinadas características que torna o risco dessa carteira superior ao risco médio da população.

A ampliação do modelo aqui proposta procura mostrar de que forma a insegurança jurídica cria restrição de crédito não apenas pelo lado do credor, mas também pelo lado do devedor. Como foi defendido na seção 2, o devedor é a parte que tem menos informação por não conhecer ou por não entender claramente as cláusulas do contrato. $\mathrm{O}$ credor não tem incentivos para informar adequada-

Outro modelo de informação assimétrica é o modelo de sinalização, em que o agente mais informado sobre a boa qualidade do produto ou serviço cria mecanismos de sinalização para diferenciar seu produto de outros com qualidade inferior. 
mente ao devedor as condições dos contratos, e o devedor não tem como pagar o custo de elaboração de contrato mais completo. $\mathrm{O}$ tomador de crédito corre riscos de que o banco tome atitudes não previstas ou previstas de forma parcial no contrato, como aumento de encargos, ou suspenda o crédito em momento difícil ou adote punições desproporcionais em situações em que o tomador se veja forçado a atrasar os pagamentos, o que aumenta de forma considerável a incerteza para o devedor sobre o custo que de fato irá suportar no relacionamento com o banco.

Dessa forma, a medida do custo de acesso ao setor bancário está associada ao custo de oportunidade de uso do crédito bancário devido à presença de assimetria de informação sobre as cláusulas do contrato. Decorre daí que a taxa de juros que o banco cobra do tomador de baixo risco será sempre maior do que a taxa que esse tipo de tomador julga que deveria pagar, dado o grau de insegurança jurídica que ele supõe que irá sofrer. Por outro lado, a taxa de juros desejada pelo devedor é sempre menor do que a taxa que o banco acredita ser justa, pois ele também incorre em custo da incerteza jurídica. Assim, a taxa cobrada pelo banco, baseada no valor esperado do retorno de empréstimo, é mais alta que a taxa esperada pelo tomador de menor risco.

Pelo fato de a taxa cobrada pelo banco ser maior que a taxa esperada pelo tomador de menor risco, esse tipo de cliente tende a sair do mercado, pois a taxa de juros do mercado $\left(i_{M}\right)$ está acima da sua taxa marginal de reserva $\left(i_{R}\right)$, ou seja, $i_{M} \succ i_{R}$.

O resultado final dessa dinâmica é que apenas o tomador de maior risco estará disposto a tomar o empréstimo, levando a uma seleção adversa em que apenas os tomadores de projetos mais arriscados tomam empréstimo, uma vez que a taxa cobrada pelo banco ainda é uma taxa abaixo da taxa de reserva desses tomadores.

Com isso, o tomador de crédito de menor risco e, portanto, de maior segurança quanto ao resultado de seu empreendimento, pode ser induzido a restringir a demanda de crédito bancário e a preferir operar com recursos próprios, o que reduziria a alavancagem geral da economia e restringiria a expansão de negócios de melhor potencial. Em paralelo, as incertezas envolvidas no crédito tornariam as operações mais atraentes para o tomador de maior risco, que aposta em retorno muito alto ou que não se preocupa tanto com o risco do negócio por ter menos a perder.

Forma-se, assim, a tendência de que as carteiras dos bancos concentrem um número elevado de tomadores para quem as incertezas sobre o próprio negócio permitem acomodar o risco de querelas com o banco e as consequências de entrar em inadimplência em algum momento. Com maior risco de inadimplência da carteira em conjunto, os bancos tendem a elevar as taxas de juros médias cobradas de todos os tomadores de crédito. 


\section{1 $O$ Lado do Devedor}

O termo seleção adversa é utilizado quando uma característica do agente é imperfeitamente observada pelo principal (SALANIÉ, 2005). Entre os principais modelos teóricos que abordam a seleção adversa em vários mercados, podemos citar Akerlof (1970) e Stiglitz e Weiss (1981) para o caso em que a seleção adversa leva ao racionamento de crédito.

Tomando como base o modelo de Akerlof (1970) de mercado de limões, o modelo aqui proposto assume a existência de dois tipos de tomadores no mercado de crédito: os que possuem projetos menos arriscados (de maior qualidade), $\varphi_{A}$, e os que possuem os projetos mais arriscados (de menor qualidade), $\varphi_{B}$.

Cada tipo de tomador considera uma taxa de juros máxima no momento da decisão de tomar o empréstimo. Sendo assim, assumimos que $r_{B}^{*}$ é a taxa máxima aceita pelo tomador de empréstimo com projeto mais arriscado, para o qual o banco aceita dar crédito. Para qualquer taxa acima dessa, o tomador está fora do mercado. Da mesma forma, haverá racionamento de crédito por parte do banco já que o risco torna-se maior que o retorno (STIGLITZ; WEISS, 1981).

Para o tomador de crédito com projeto menos arriscado há, pelo menos, duas situações prováveis que devem ser levadas em consideração no momento da contratação do empréstimo. Ao tomar o empréstimo, o devedor não sabe previamente se terá ou não problemas com o credor. Sabe-se, portanto, que se houver um problema que não seja possível resolver diretamente entre as duas partes, sendo, portanto, necessário recorrer à decisão da justiça, a insegurança jurídica também afetará o tomador de crédito. No entanto, o devedor sabe que há uma probabilidade de o resultado da justiça ser desfavorável a ele. Chamaremos essa probabilidade de $\theta$.

O tomador, portanto, toma a sua decisão levando em conta que o juiz poderá decidir contra, com probabilidade $\theta$, e que a decisão do juiz poderá ser favorável com probabilidade $1-\theta$. A variável $\theta$ capta a presença de insegurança jurídica. Quanto maior $\theta$, maior a probabilidade de haver a insegurança jurídica. Quanto menor for o $\theta$, menor é a probabilidade.

Dessa forma, temos:

a) situação em que o juiz decide a favor do tomador de crédito: nesse caso, o tomador não necessitaria incorrer em custos com a justiça. Assim, assumimos que a taxa de juros máxima requerida pelo tomador de crédito com projeto bom (preço de reserva) é $r_{A}^{f}$. Acima dessa taxa, não toma empréstimo;

b) situação em que a decisão do juiz é contra o tomador de crédito: nesse caso, há um custo adicional de recorrer à justiça, pois a decisão desfavorável obriga o tomador a arcar com todos os custos do processo. A 
taxa de juros requerida, assim, seria $r_{A}^{c}$. Acima dessa taxa, não toma empréstimo.

Como não há certeza por parte do tomador se a decisão por parte do juiz será favorável ou não, o tomador vai requerer uma taxa que será o valor esperado entre as duas taxas. A nova taxa agora será expressa por um valor esperado entre a taxa requerida no caso em que a decisão do juiz é favorável $\left(r_{A}^{f}\right)$ e a taxa caso a decisão do juiz seja contra $\left(r_{A}^{c}\right)$. Nesse caso, temos que o tomador aceita pagar uma taxa de juros maior caso tenha certeza de que o juiz decidirá a seu favor e uma taxa menor caso tenha certeza de que o juiz decidirá contra, uma vez que a decisão desfavorável do juiz aumenta o custo do tomador. Sendo assim, temos que $r_{A}^{f} \succ r_{A}^{c}$.

Por conta da assimetria de informação, o tomador de empréstimo conhece apenas o comportamento médio dos bancos. Como o custo de obter mais informação sobre o banco com que está negociando é muito alto, o tomador de empréstimo aceita se endividar pagando uma taxa média entre as duas taxas.

Genericamente podemos representar os dois resultados possíveis por $r_{A}^{f} \mathrm{e}$ $r_{A}^{c}$, que são as probabilidades de cada resultado indicadas por $\theta$ e $1-\theta$. Temos, então, a seguinte equação para o valor esperado das taxas:

$$
E\left(r_{A}\right)=\theta\left(r_{A}^{c}\right)+(1-\theta)\left(r_{A}^{f}\right)
$$

Sendo $E\left(r_{A}\right)$ o valor esperado entre as duas taxas. Por definição temos que

$$
r_{A}^{c} \prec E\left(r_{A}\right) \prec r_{A}^{f}
$$

A suposição aqui assumida é que o custo da insegurança jurídica para o tomador do tipo B (de projeto mais arriscado) é irrelevante para a sua tomada de decisão, uma vez que já é grande a possibilidade de não conseguir honrar o contrato.

Ocorre que do lado do credor há também a incerteza associada ao tipo de tomador de crédito e também à insegurança jurídica, o que faz com que a taxa de juros seja definida considerando o risco médio do mercado associado com o custo da insegurança jurídica do lado devedor, o que eleva a taxa de juros acima da taxa aceita pelo tomador de menor risco.

\subsection{O Lado do Credor}

Um banco, ao conceder crédito, espera obter o maior retorno esperado possível, no entanto, o maior retorno depende da probabilidade de pagamento por parte dos tomadores de empréstimos, assim como da taxa de juros a ser cobrada.

Do lado do credor o problema da seleção adversa aparece porque o banco pode incorrer em queda do retorno esperado do crédito concedido. Por exemplo, 
isso pode ocorrer no caso de um default involuntário, que ocorre em situações em que o tomador não tenha sucesso no seu projeto financiado e não possua outras fontes de recurso para cumprir o contrato e pagar a sua dívida. Este é um caso de default involuntário, porque se supõe que em caso de sucesso do projeto haveria cumprimento do contrato.

O banco, portanto, gostaria de conceder empréstimos para tomadores com projetos de menor probabilidade de default e cobrar maior taxa de juros para aumentar o seu retorno. No entanto, ele se defronta com vários tipos de tomadores (com projetos de baixo risco e alto risco) com diferentes probabilidades de cumprir o pagamento do empréstimo.

Os tomadores que possuem projetos de menor risco gostariam de pagar taxas menores. Nesse sentido, o banco se vê diante de um trade-off. Ao elevar as taxas de juros, o banco eleva o seu retorno, porém tende a selecionar tomadores com projetos de maior risco, dessa forma levando à seleção adversa.

Os problemas da seleção adversa e insegurança jurídica levam o banco a formar uma taxa de juros no mercado de crédito acima da taxa de equilíbrio que maximiza o seu retorno esperado. Stiglitz e Weiss (1981) demonstraram que há para o credor uma taxa de juros que maximiza o retorno esperado de seu pool de empréstimos, utilizando a relação de risco e retorno do credito concedido. ${ }^{2} \mathrm{Se}$ a taxa de juros formada nesse mercado fosse capaz de equilibrar a oferta e a demanda de crédito, não haveria espaço para o racionamento de crédito. Entretanto, não é essa a situação que se observa no mercado brasileiro.

Para demonstração do lado do credor tomaremos como base o modelo de racionamento de crédito de Stiglitz e Weiss (1981), acrescentando, além da probabilidade do retorno esperado, mais uma variável de incerteza, que capta o efeito do problema da insegurança jurídica a que o banco está exposto caso o contrato não seja cumprido pelo devedor.

O problema com que o credor se depara para a sua tomada de decisão de quanto deverá ser a taxa cobrada pelo empréstimo pode ser representado da seguinte forma:

Considere $X$ sendo o valor do empréstimo, $\phi$ a probabilidade de o tomador honrar o pagamento do valor do empréstimo e $(1-\phi)$ a probabilidade do não pagamento. $\tau$ é o custo do banco em recorrer à justiça no caso do não pagamento e $\gamma$ é a probabilidade do resultado da justiça ser favorável ao banco. A variável $\gamma$ capta a presença de insegurança jurídica.

O credor, portanto, faz o seguinte cálculo para definir a sua taxa de juros:

$$
E(X)=\phi X+[(1-\phi)(-\tau+\gamma X)]
$$

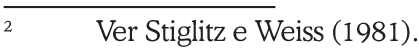


Em que $E(X)$ é o valor esperado do retorno do empréstimo.

Por definição, $E(X) \prec X$, portanto, o credor define a sua taxa de juros considerando essa perda esperada, que é muito acima da taxa cobrada, caso tivesse a certeza do retorno do empréstimo sem o custo da incerteza jurisdicional. Da mesma forma, essa taxa é muito mais alta do que a taxa esperada do bom tomador, representada pela equação 1 .

O resultado final dessa dinâmica é que o tomador de maior risco é incentivado a tomar empréstimo e o tomador de melhor risco é levado a tomar atitudes mais cautelosas, levando a uma seleção adversa nesse mercado, uma vez que a taxa cobrada pelo banco ainda é uma taxa abaixo da taxa de reserva do tomador de maior risco.

Tal como mostrado pelo modelo de Stiglitz e Weiss (1981), à medida que o credor percebe que a maioria dos tomadores de crédito é de alto risco, eleva mais ainda a taxa de juros, o que contribui para o aumento da proporção de empréstimos mais arriscados. Essa sequência de aumentos na taxa de juros continua até que o mercado se equilibre num ponto sub-ótimo, caracterizado por uma proporção muito alta de projetos mais arriscados, entre os que obtêm financiamento e por uma demanda de crédito inferior às possibilidades de alavancagem dos projetos de melhor qualidade. Em outras palavras, por haver informação assimétrica e insegurança jurídica, há no mercado de crédito um equilíbrio sub-ótimo, em que o endividamento e alavancagem estão abaixo do que seria possível num contexto de maior segurança jurídica.

\section{Considerações Finais}

O trabalho defendeu que sejam estendidas aos riscos do devedor as análises sobre as implicações da insegurança jurídica para a oferta e o custo do crédito no Brasil, com base em argumentos teóricos e empíricos, além de propor a inclusão da insegurança jurídica do devedor no modelo teórico de racionamento de crédito.

Com base na nova economia institucional, sustentou-se que, devido aos altos custos de transação e à racionalidade limitada dos agentes econômicos, os contratos no mundo real tendem a ser incompletos. Para resolver conflitos derivados desses contratos, é preciso identificar o tomador de risco mais eficiente, que é a instituição credora, enquanto o tomador de empréstimo é a parte hipossuficiente, a parte mais frágil no contrato, devido à assimetria de informação sobre o mercado de crédito e sobre o próprio contrato.

Em seguida, o trabalho criticou o tratamento unilateral e simplificado que o debate econômico brasileiro dispensa ao tema, inclusive pela ausência de comprovação empírica. A análise das decisões proferidas pelo STJ, no período de ou- 
tubro de 1998 a outubro de 2008, referentes a processos envolvendo dívidas contratuais entre partes privadas, não comprovam a existência de viés pró-devedor nas decisões do STJ.

Assim, a questão da presença de viés pró-devedor ou pró-credor é muito mais complexa e certamente é não uniforme, ao contrário do que defendem Arida, Bacha e Lara-Resende (2005), e requer mais estudos empíricos.

$\mathrm{Na}$ seção final, o trabalho desenvolveu uma proposta para inclusão da insegurança jurídica do devedor no modelo de racionamento de crédito com base na tese de que a insegurança jurídica do devedor causa redução do crédito e da alavancagem da economia em prejuízo dos melhores projetos e elevação do risco das carteiras dos bancos e do custo dos empréstimos para os tomadores. O debate sobre as relações entre insegurança jurídica e alto nível de spreads bancários no Brasil deveria incluir também os problemas enfrentados pelos tomadores de crédito.

\section{Referências}

AKERLOF, G. The market for lemons: quality uncertainty and the market mechanism. Quarterly Journal of Economics, v. 84, n. 3, p. 488-500, 1970.

ARIDA, P.; BACHA, E.; LARA-RESENDE, A. Credit, interest, and jurisdictional uncertainty: conjectures on the case of Brazil. In: GIAVAZZI, F.; GOLDFAJN, I.; HERRERA, S. (Org.). Inflation targeting, debt and the Brazilian experience. Cambridge, MA: MIT Press, 2005. p. 265-293

AZEVEDO, P. F. Economia dos contratos - Parte II. In: SZTAJN, R.; ZYLBERSZTAJN, D, Direito $\mathcal{E}$ Economia. Rio de Janeiro: Elsevier, 2005.

BALLARD, M.. The clash between local courts and global economics: the politics of judicial reform in Brazil. Berkeley Journal of International Law, v. 17, p. 230-276, 1999.

BANCO CENTRAL DO BRASIL. Economia bancária e crédito: avaliação de cinco anos do projeto juros e spread bancário. Brasília, Departamento de Estudos e Pesquisa, Relatório de Economia Bancária e Crédito, 2004.

COASE, R. The nature of firm, Economica, New Series, v. 4, n. 16, p. 386-405, Nov. 1937.

COASE, R. The problem of social cost. Journal of Law and Economics, v. 3, p. 1-44, Oct. 1960.

COOTER, R.; ULEN, T. Direito e Economia. 5. ed. Porto Alegre: Bookman, 2010.

FALCÃO, J.; SCHUARTZ, L. F.; ARGUELHES, D. W. Jurisdição, incerteza e Estado de Direito. Revista de Direito Administrativo, n. 243, set./dez. 2006.

FERRÃO, B.; RIBEIRO, I. C. Os juízes brasileiros favorecem a parte mais fraca? In: TEIXEIRA, C. E.; Braga M. J. (Org.). Instituições e desenvolvimento econômico. Viçosa: Editora UFV, 2007. p. 245-282.

GAIO JUNIOR, A. P. Direito Processual Civil. v .1. São Paulo: Del Rey, 2008.

GOLEK, N. B. M. Os usos e abusos das instituições de crédito. Jornal dos Economistas, Rio de Janeiro, n. 197, p. 12-13, dez. 2005. 
GONÇALVES, F. M.; HOLLAND, M.; SPACOV, A. Can Jurisdictional uncertainty and capital controls explain the high level of real interest rates in Brazil? Evidence from panel data. Revista Brasileira de Economia, v. 61, n. 1, p. 49-75, Jan.-Mar. 2007.

LAMOUNIER, B.; SOUZA A. As elites brasileiras e o desenvolvimento nacional: fatores de consenso e dissenso. São Paulo: Instituto de Estudos Econômicos, Sociais e Políticos de São Paulo, 2002.

SIMON, H. Bounded rationality and organizational learning. Organization Science, v. 2, n. 1. Special Issue: Organizational Learnings: Papers in Honor of (and by) James G. March, p. 125-134, Feb. 1991.

STIGLITZ, J. E.; WEISS A. Credit rationing in markets with imperfect information. The American Economic Review, v. 71, n. 3, p. 393-410, June 1981.

SALANIÉ, B. The economics of contracts: a primer. 2. ed. Cambridge: MIT Press, 2005.

SILVA, D. L. O procedimento judicial e o custo do dinheiro para pessoas jurídicas no mercado de crédito bancário no Brasil (1994-2004). 2006. 144 f. Dissertação (Mestrado em Economia) - Pontifícia Universidade Católica de São Paulo, São Paulo, 2006.

SZTAJN, R.; ZYLBERSZTAJN, D. Economia dos contratos. - Parte I. In: ZYLBERSZTAJN, D.; SZTAJN, R. Direito 8 Economia. Rio de Janeiro: Elsevier, 2005. p. 102-112.

VEÇOSO, F. F. C. et al. A pesquisa em direito e as bases eletrônicas de julgados dos tribunais: matrizes de análise e aplicação no supremo tribunal federal e no superior tribunal de justiça. Revista de Estudos Empíricos em Direito, v. 1, n. 1, p. 105-139, jan.2014.

Recebido em: 14/10/2012.

Aceito em: 24/09/2013. 